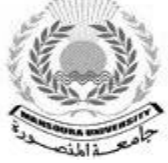

Mansoura University

Faculty of Tourism and Hotels

\title{
EXPLORING BARRIERS OF KNOWLEDGE MANAGEMENT IMPLEMENTATION KMI IN EGYPTIAN HOTEL INDUSTRY
}

\author{
$B y$
}

Dr/ Eslam Ahmed Fathy Fathy

Faculty of Tourism and Hotel

Management, Pharos University, Alexandria, Egypt.

\section{RESEARCH JOURNAL OF THE FACULTY OF TOURISM AND HOTELS \\ MANSOURA UNIVERSITY}

ISSUE NO. 10, DECEMBER. 2021 
Exploring Barriers of Knowledge Management Implementation KMI in Egyptian Hotel Industry 


\title{
Exploring Barriers of Knowledge Management Implementation KMI in Egyptian Hotel Industry \\ By \\ Dr. Eslam Ahmed Fathy Fathy ${ }^{1}$
}

\begin{abstract}
Purpose: The current study aim to investigate and model the Knowledge Management Implementation (KMI) barriers, as well as suggesting some overcoming strategies to cope with KMI barriers .
\end{abstract}

Design/methodology/approach: It has employed a quantitative method by developed a questionnaire based on the literature and distributed it among hotel employees in Four and Five-star hotels in Alexandria in Egypt. A total of 386 valid questionnaires were analyzed by SEM .

Findings: Results of the path analysis indicated that barriers of the organizational culture and human resources have a positive impact on KMI. However, the technology infrastructure barriers have a negative impact on KMI .

Originality/value: A major concern of hotel to increase the hotel performance with high level of employees' turnover, this study provides an inclusive investigation of KMI barriers in hotel industry. Also, it explores strategies to overcome the KMI barriers .

Practical Implications: In order not to deprive Egyptian hotels from KMI benefits, the study suggested practical implications to enable them overcoming the KMI barriers,

\footnotetext{
${ }^{1}$ Faculty of Tourism and Hotel Management, Pharos University, Alexandria, Egypt.
} 
such as providing a creative, motivating, and rewarding organizational culture to increase the knowledge exchange. In addition to a KM System that has been designed based on smart phone applications. Transformational leadership and KM training courses were essential to create an environment of teamwork, trust, knowledge exchange, and learning.

Keywords: Knowledge Management Implementation, KMI, Human resources Barriers, Technology Infrastructural Barriers, Organizational cultural Barriers, Hotel.

\section{Introduction}

Over recent decades, the Knowledge Management(KM) approach has been widely recognized; based on being a prerequisite for survival, success, and creativity in today's fiercely competitive marketplace in hospitality organizations (Cooper, 2014), in order to improve innovative behavior in hotels, and lead to the improvement of hotel performance (Salem, 2014). Knowledge society has used the knowledge and information as a critical tool to serve customers. Thus, information and knowledge now play a very crucial role in the economy (Hislop, et al., 2018), it allows many organizations to cultivate the knowledge of the customers, employees, suppliers, and competitors (Sigala, 2016) to maintain the competitive advantages in the high intensive market where customers are constantly looking for the best deals that meet their continuous changing needs to sustain long-term revenues and profits (Jogaratnam, 2017).

In the hotel industry staff turnover is generally acknowledged to be high, which often leads to loss of human capital, leakage of expertise and knowledge 
acquisitions (Fathy, 2018), decrease in the service quality, particularly if employees did not exchange their experience with coworkers, and when the hotel didn't document the employees' experiences (Yang, 2004). Thus, the process of retaining knowledge must be structured by incorporating it in a documented form to all uncommon situations and best practices (Levy, 2011). Hence, the importance of KM in the hospitality industry emerged to overcome such challenges and the need to investigate the KM implementation barriers, which add value to both the hospitality industry and human resources (Črnjar and Dlačić, 2014 .(

Knowledge management in the hospitality industry has developed over the last era to become, along with the existing efforts in KM practices, one of the most argued management concepts. However, there are few major chains, such as Hilton, Accor that are interested in KMI, KM benefits, and the learning environment (Cooper, 2006; Hallin and Marnburg, 2007). In fact, the continuous customers' changing needs, and the aggressive competition, definitely heightened the hospitality industry need to be highly knowledge-intensive (Kahle, 2002). Thus, KM strategies become more indispensable to achieving and enhancing excellence and creativity. Nevertheless, there are various barriers that hinder KMI in the hotel industry in Egypt, Alexandria, which undoubtedly deprive the industry from KMI benefits.

Actually, studies to assess KMI barriers in the hospitality industry are limited (Cheng, 2010). Thus, many studies need to be conducted to investigate the KM barriers especially in the Egyptian hotel context. The current study aims at developing a model of KM barriers in the Egyptian hotel industry, and offering approaches for hotels to reduce 
these obstacles. Consequently, three objectives were considered as following. Firstly, developing a conceptual model for examining the barriers hindered KMI in hotels. Secondly, investigating the organizational culture, human resources, and technology infrastructure barriers related to KMI. Thirdly, developing effective strategies to overcome the KMI barriers in hotel industry. The current study provided a tangible successful application for overcoming the barriers of KMI which will undoubtedly help in reaching the hotels required objectives. Thus, assessing KM barriers became imperative to improve the efficiency of $\mathrm{KM}$ in hotel industry in Alexandria, Egypt. The current study pursues to provide a contribution to the proposed model for the KMI, and strategies to overcome barriers of KMI.

\section{Literature Review}

\section{Knowledge Management (KM)}

Researchers and academics defined KM in a variety of viewpoints. Rowley (2000) defined it as knowledge that is prepared and used to achieve the business's aims. It seems that the KM definition is usually tied to specific organizational objectives, such as the improved performance and strategy planning. Similarly, Cooper (2006) defined it as " the application of the available knowledge assets in an organization to create a competitive advantage". The main purpose of $\mathrm{KM}$ is not only to manage all available knowledge, but also to manage the effective and efficient Knowledge which is considered a core competence for the improvement and prosperity of business in the hyper-competitive to achieve the organizational goals 
(Zeraati et al., 2019; Schmitt, 2019). Consequently, KM could enhance creativity and innovation of products and services delivered to customers (Salem, 2014), since knowledge capture improves rapid absorption and diffusion of new ideas, operational efficiency, and organizational growth (Hari, et.al., 2005), by reuse of Knowledge with recent technology (Boroujerdi et al., 2020).

\section{Conceptual framework and hypotheses development}

\section{KM Barriers}

Barriers of KM as suggested by Long (1997) are categorized into organizational culture, and technology infrastructure. Recently, Črnjar and Dlačić (2014) added the human resource factor as a barrier in KM implementation.

Human Resources (HR) Barriers.

Črnjar and Dlačić (2014) concluded the potential barriers of HR as being cultural effects, personal anxiety (Professional territorialism), change resistance, and inadequate motivation policy (Hong, et al., 2009). Firstly, the staff either doesn't prefer to share their knowledge with others as they are frightened to lose their job, or they share it only with selected employees (Uriarte, 2008). In the similar vein, some managers seem to be afraid of sharing their knowledge, totally or partially, regarding the rapidness of their subordinates' growth and promotion than themselves, which might lead them to lose their positions and lack trust. They consider knowledge a source of power, success, support, and back-room deals. Firstly, the 
aforementioned cause reluctance to exchange knowledge among employees, this leads to limited KMI in small group or people, resulting in obstructing KMI (Yih-Tong and Scott, 2005). Second, Yuen (2007) stated that employees are constantly resistant to change in processes, systems, or applications of a new system, due to their lack of acceptable familiarization and understanding of any recent system. Third, another obstacle was reported by Yang and Wan (2004), which is the reluctance to knowledge sharing that takes place when shared ideas involve changing daily operations, attitudes of shareholders and shares, and the absorptive capacity of recipients. The above-mentioned barriers impede the cooperation and collaboration among employees. This actually implies that HR can have negative effects on the KMI in hotels. This leads to the first hypothesis (Figure1):

H1: Human resource barriers have a negative impact on $\mathrm{KMI}$ in Alexandria hotels in Egypt.

\section{Technology Infrastructure (TI) Barriers.}

Riege (2005) supposed the technological barriers of KM may be summed up as following:

- Legacy systems cause lack of integration between system and operation process.

- Improper software system for business operation.

- Lack of maintenance and updating of the software and hardware, technical support of IT systems obstructs the communication flows and knowledge sharing. 
- Employees are unable to predict what the new technology can do and cannot do.

- Mismatch between integrated IT systems and individuals' need requirements limits sharing process.

- Lack of understanding, training, familiarization and experience of knowledge management aims, use and benefits; increase the resistance to use new KM systems.

Based on the previous research, it can be assumed that technology may has an effect on the KMI, which obviously leads to the third hypothesis:

H2: Barriers of technology infrastructure has a negative impact on KMI in Alexandria hotels in Egypt.

\section{Organizational Culture (OC) Barriers.}

Firstly, McDermott and O’Dell (2001) posit culture as one of the key inhibitors of KM implementation. To illustrate, a culture must be created to enhance the knowledge sharing and acceptance of $\mathrm{KM}$ to increase its proficiency. Milam (2001) stated that the most significant barrier of KM was organizational culture OC. He also stressed that the effective Knowledge Management System KMS must involve the staff (knowledge community), who uses, shares, and transfers the knowledge. Consequently, if the organization has improper OC, such as absence of the reward system to exchange knowledge, absence of methods of encouraging cooperation among employees, or absence of leadership support, this would definitely hinder the KMI 
(Khajouei et al. 2016). Therefore, it does make sense to argue that barriers of OC can significantly affect KMI in hotels. Occasionally, this leads to the first hypothesis as following (see figure 1):

H3: An organizational culture barrier has a negative impact on KMI in Alexandria hotels in Egypt.

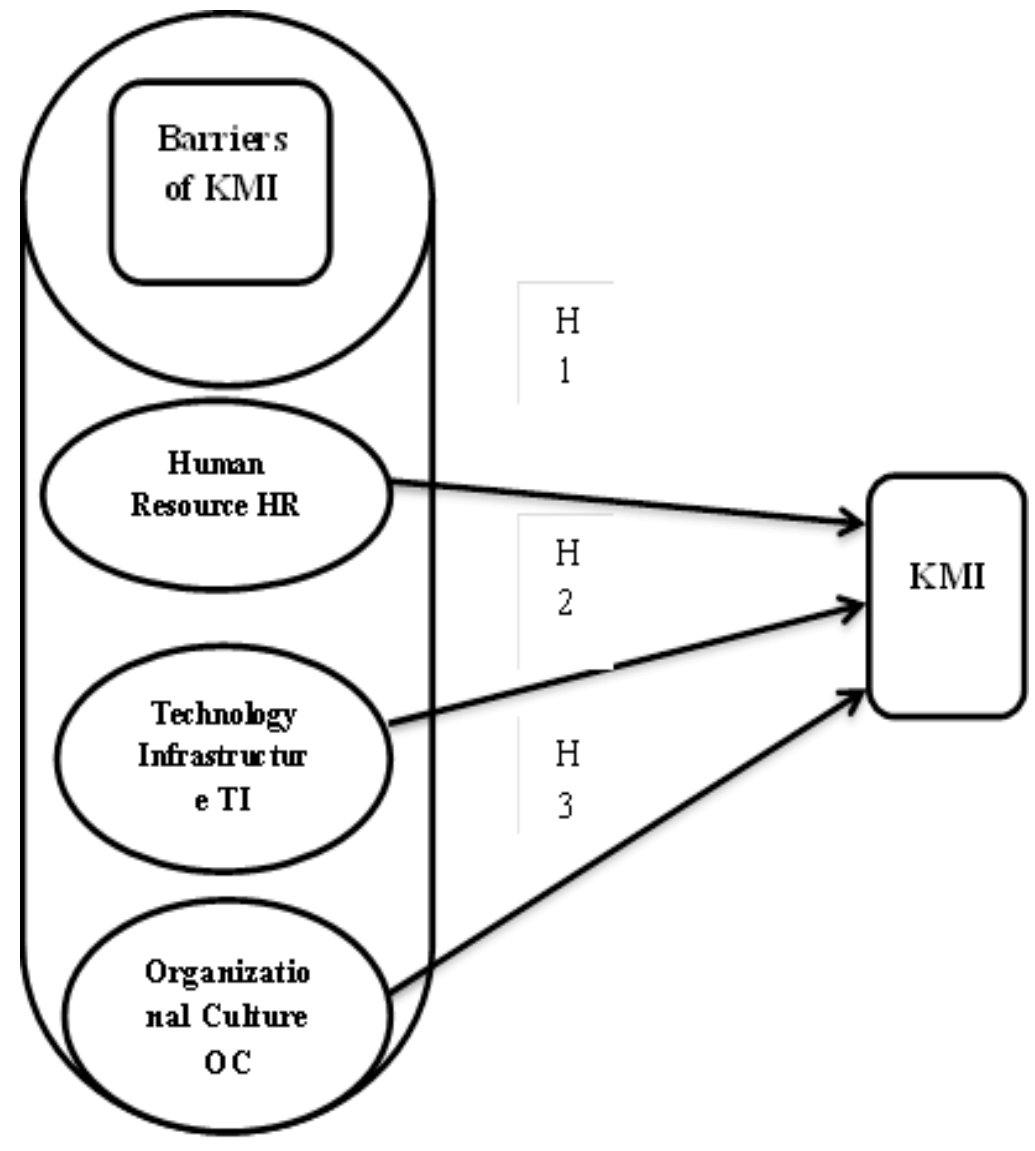


Figure. 1. The Conceptual model and the research hypotheses

\section{Research Methodology}

\section{Research Approach and Sampling Method.}

The current study has been conducted to recognize the main barriers to KM that obstructed the KMI in Four and Five-star hotels in Alexandria, Egypt. The Egyptian hotel association recognized 11 hotels as the population (Seven 5-star-hotels and Six 4-star hotels). Four and Fivestar hotels were chosen due to their high technological infrastructure, and their ability to adopt trendy management concepts than lower hotel grades.

The population of the current study consists of employees from Four and Five-star hotels in Alexandria, Egypt. The exact number of employees working in the 4-star 5-star hotels is not available in the hotel association establishment. Thus, the current researcher obtained the data from the human resources departments at the 4-star and 5-star hotels, which showed to be 1570 employees. According to this number of employees, a purposive sampling technique was used in the current study. A sample of 258 employees worked in 5 star hotels and 128 employees worked in 4 star hotels with a percentage of more than $25 \%$ is approved as recommended by Gay and Diehl (1992). The questionnaire was distributed among most knowledgeable employees, who depend on knowledge management in the accomplishment of their tasks in different hotel departments. 
The study employs the quantitative approach, using a questionnaire to collect data. This is considered to be the most common data collection method in hospitality researches that can be underused to statistically analyze and investigate a status of the chosen sample with respect to the tested variables (Neuman, 2003).

\section{Questionnaire Development and Data Collection.}

At the primary stage of the questionnaire development, a fairly extensive literature review was performed to gather relevant questions (Črnjar and Dlačić , 2014; Hong, et al., 2009; Uriarte, 2008; Yuen, 2007; Riege, 2005; Milam 2001, Khajouei et al. 2016) to the variables selected in the study framework to ensure that the questionnaire items can assess the study's variables properly. The questionnaire language and the use of hotels related terms and idioms were also put into consideration. The questionnaire was revisited by three methods. Firstly, some survey design statistics experts checked the questionnaire's readability, ambiguity, and completeness. Second, four researchers in KM experts suggested adding or removing items. Their expert comments were included in the questionnaire editing, which have a vital role in preventing the insertion of unclear questions. Third, a pilot study was conducted among potential respondents of 20 hotels' employees of four and five-star hotels, to ensure that the questionnaire is welldesigned and easily understood. It was answered by potential respondents within ten minutes, and thus the final version of the questionnaire launched after the inclusion of pilot study comments. The questionnaire utilized in the present study consists of questions that were formulated to 
test the study hypotheses, assessing by 5 -point Likert scale ranging from strongly disagree (1) to strongly agree (5). The researcher sought to find out the barriers that influence the KMI in Alexandria hotels in Egypt. The questionnaire was distributed among employees during the period of April-December 2019, and a total of 386 questionnaires were collected from 520 questionnaires distributed giving a response rate of $74.23 \%$. According to Kline (2011) 386 questionnaires are considered and enough to carry out in SEM analysis.

\section{Results and analysis}

\section{Respondents' Profile.}

The questionnaire yielded a sample of 386 employees after deletion of incomplete responses and outliers. Respondents' ages ranged from 21to 51 years with an average age of 46 . Most of the respondents were, 48 percent worked in the front of the house (e.g. front desk and concierge) and 52 percent worked in the other hotel sections (13\% kitchen, 19\% Restaurants, $11 \%$ Sales and Marketing, 5\% Housekeeping, and 4\% other sections). About 52 percent the majority was line-level employees and $48 \%$ was managers' levels.

This research used the two-step approach (Anderson and Gerbing, 1988). First, the measurement model was specified and carried And CFA was illustrated in (figure 2) performed with three second-order measurements $(\mathrm{x} 1=$ organizational culture, $\mathrm{x} 2=$ technology infrastructure, and $\mathrm{x} 3=$ human 
resources) and one first-order measurement (DV=knowledge management).

To ensure a good model fit, a second run of SEM using AMOS software was applied to conduct the confirmatory factor analysis to determine whether the corresponding dimension reflected the observed variables and latent constructs for the full measurement model.

The second AMOS trial helped to modify the model as some variables was dropped out due to their low factor loadings. Second, structural equation modeling was conducted to measure the hypothesized relationships among the constructs. 


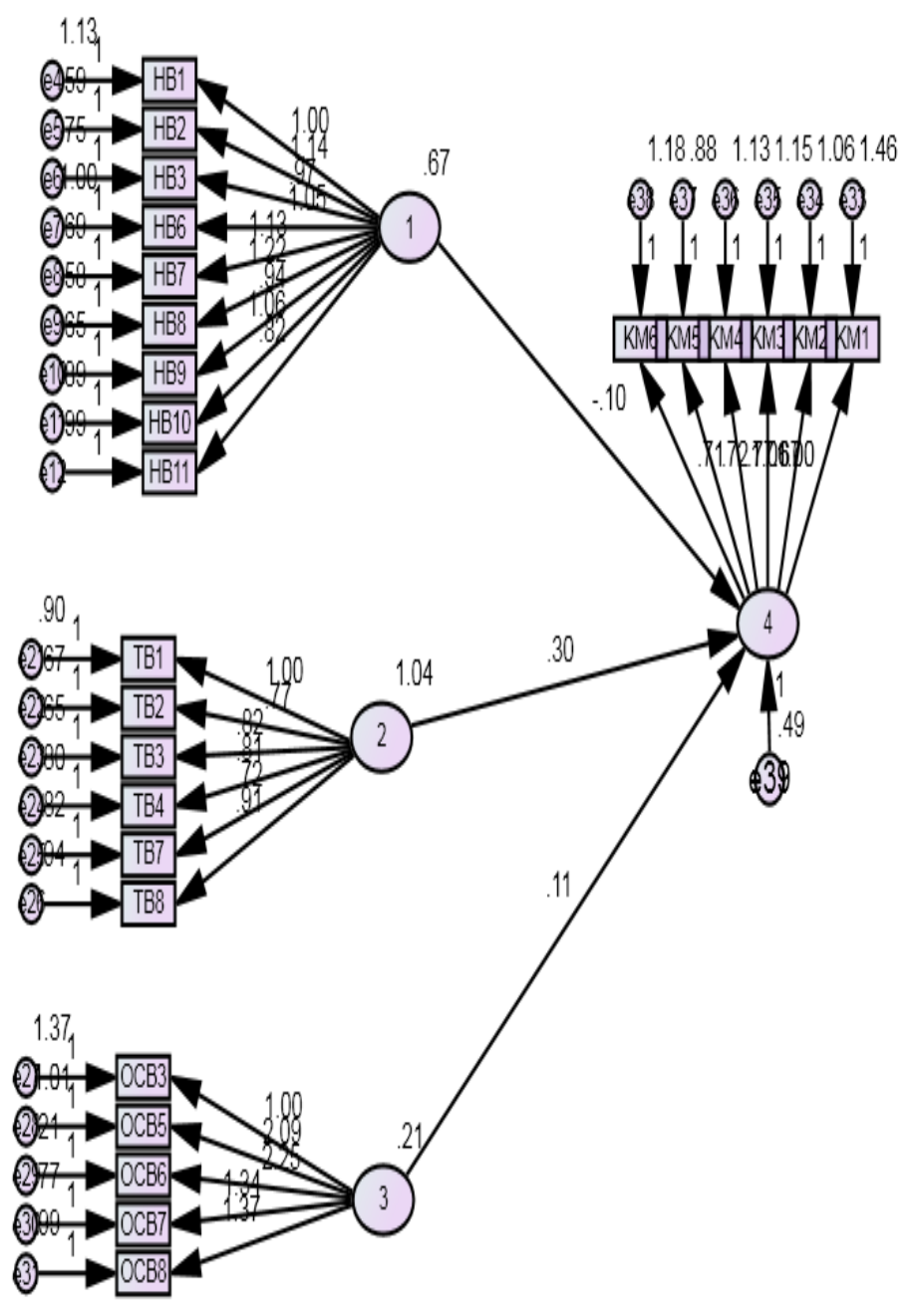

Note: $1=$ Human resource barriers, $2=$ Technology barriers, $3=$ organizational barriers, and $4=\mathrm{KM}$. 


\section{Figure 2. Structural Model}

\section{Measurement Model Fit Indices.}

The hypothesized relationships in the current study were tested using AMOS 25. The global goodness-of-fit indices show that the structural model represents the data structure well: Chi-square $=727.086$, root mean square error of approximation (RMSEA) is . 719, comparative fit index (CFI) is . 090, CMIN / df (269) is 2.456 with Probability level $=.000$ (Barbara, 2010).

Factor ladings, CR , SE, and path analysis were highlighted in Table 1.

Table 1. Regression weights of the path analysis and convergent validity

\begin{tabular}{rllllllll}
\hline \multicolumn{2}{c}{ Relationships } & & Estimate & S.E. & C.R. & P & \multicolumn{2}{c}{$\begin{array}{c}\text { Cronbach's AVE } \\
\boldsymbol{\alpha}\end{array}$} \\
\hline 4 & $<---$ & 1 & -.100 & .095 & -1.046 & .296 & \\
4 & $<---$ & 2 & .302 & .093 & 3.258 & .001 & \\
HB1 & $<---$ & 3 & .110 & .173 & .637 & .524 & & \\
HB2 & $<---$ & 1 & 1.000 & & & & .78 & .66 \\
HB3 & $<---$ & 1 & 1.135 & .154 & 7.365 & $* * *$ & \\
HB6 & $<---$ & 1 & .974 & .145 & 6.715 & $* * *$ & \\
HB7 & $<---$ & 1 & 1.051 & .161 & 6.518 & $* * *$ & \\
HB8 & $<---$ & 1 & 1.125 & .157 & 7.167 & $* * *$ & \\
HB9 & $<---$ & 1 & 1.221 & .162 & 7.519 & $* * *$ & \\
& $<---$ & 1 & .937 & .138 & 6.793 & $* * *$ &
\end{tabular}




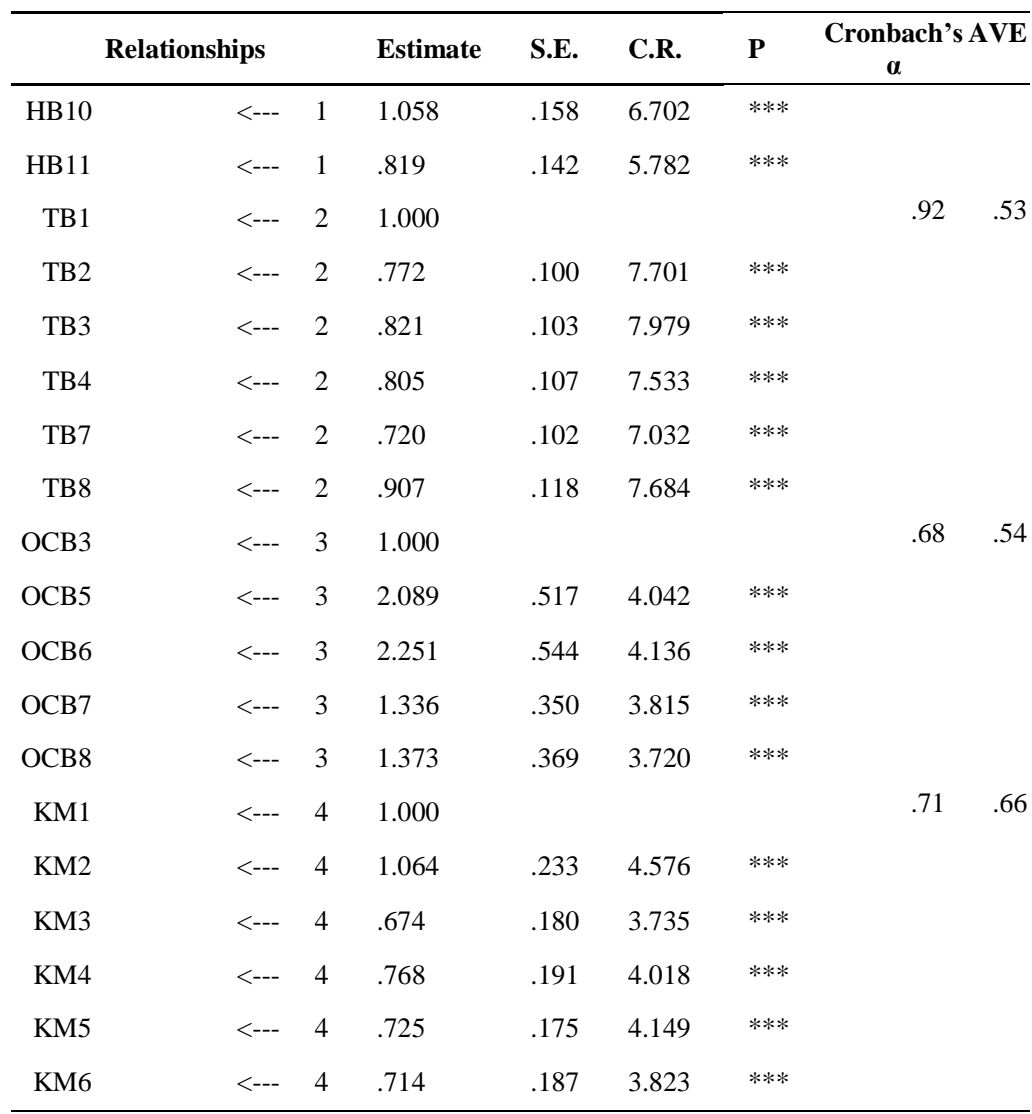

Table 1 shows CFA results with a range of factor loadings for every item, from 0.436 to 0.912 , and all were significant. Moreover, average variance extract (AVE) greater then 0.50 and composite reliability (CR) values exceeded the criterion of AVE > 0.50 and construct composite reliability $(\mathrm{CCR})>0.60$ (Hair et al., 2014). Also, all factor loadings ranged from 0.736 to 0.976 , and t-values representing all factor loadings of the multi-dimension were significant as shown in figure 2. Moreover, The AVEs of 
multi-dimensions and the CRs surpassed the threshold 0.50 and 0.60 respectively (Hair et al., 2014). Thus, the measurement model had appropriate convergent validity. As shown in Table 1, Cronbach's were all above 0.70 and represent higher consistency and validity of the constructs (Nunnally, 1978). Furthermore, comparing the AVE values with the squared values of coefficients correlation among model construct, it has proved that AVE values were greater than the squared correlations as shown in table 2 . Thus, the measurement model had sufficient discriminant validity (Fornell and Larcker, 1981).

\section{Table 2: Discriminant validity.}

\begin{tabular}{llrrrr}
\hline & & 1 & 2 & 3 & \multicolumn{1}{c}{4} \\
\hline 1 & KMI & $(.66)$ & & & \\
2 & OCBs & $.032^{*}$ & $(.54)$ & & \\
3 & HBs & $.028^{*}$ & $.432^{* *}$ & $(.66)$ & \\
4 & TBs & $.061^{* *}$ & $.339 * *$ & $.115^{* *}$ & $(.53)$ \\
\hline
\end{tabular}

Note:

The numbers in the diagonal line (values in parentheses) are AVE.

The numbers in the cells of off-diagonal line are squared correlation coefficients of one factor with another factor. $* *$ refer to significance level of 0.01 .

* refer to significance level of 0.05 .

\section{Hypotheses Testing.}


Figure 3 showed SEM results which supported Two hypotheses from Three. First, HR barriers and the perceived knowledge management revealed that HR barriers have a direct positive effect on KM dimension. The path coefficient between them is 0.296 with high significance $\mathrm{P}$ value level $(\mathrm{P}<0.001)$. This highly significant $(\mathrm{P}<0.001)$ path coefficient provides an evidence to reject the null hypothesis (no relationship exists). Second, the path coefficient between organizational barriers and the perceived $\mathrm{KM}$ is 0.524 with high significance $\mathrm{P}$-value $(\mathrm{P}<0.001)$. Third, the path coefficient between the technology infrastructure barriers factor and $\mathrm{KM}$ is 0.001 with no significant value, so the null hypothesis was supported.

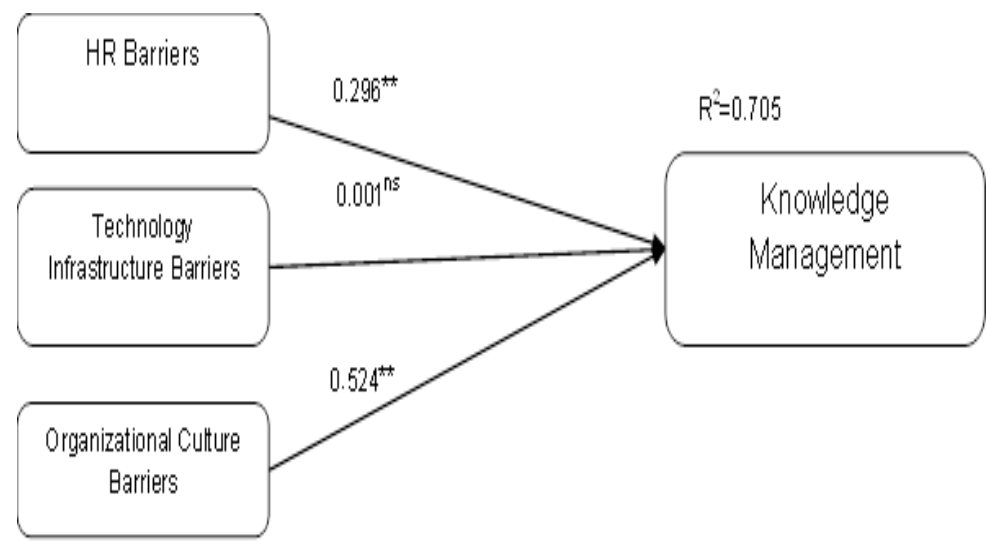

ns= Not Significant "Significantat $0.01 \quad$ Note: Significant at 0.05

Figure 3: The path model and hypotheses testing 


\section{Discussion and Conclusions.}

Regarding $\mathrm{KM}$ as a growing prerequisite for success in today's fiercely marketplace, the current research attempts to investigate and model the barriers of KMI through achieving the research's objectives. Consequently, recognizing KMI barriers allows hotels to develop strategies to overcome them. Actually, the first and second study objectives are to model and investigate the HR, OC, and TI barriers related to KMI. The analysis of the association between HR and KMI proves that the barriers of HR can simultaneously limit the benefits of KMI. The current study is partially consistent with findings of Črnjar and Dlačić (2014), Hong, et al., (2009) Uriarte (2008). It showed that employees were anxious to lose their job if they shared their experience with colleagues, they fear of others stealing their ideas, and fear their rapid subordinate' promotion. Moreover, the current study identified many of the HR barriers prohibiting KMI, such as absence of communication skills (verbal/written) and social network among hotels' employees. It showed that lack of trust in the accuracy and credibility of knowledge source, lack of employees' skills to share or transfer their experiences, the sharing difficulty of tacit knowledge, and the lack of time for training on knowledge technology procedures, are all obstacles to KMI.

As a matter of fact, the findings of the current research showed that the TI barriers had no significant effect on KMI. However, the interviews' results highlighted the main 
TI barriers in hotels, which are lack of integration between IT systems and work procedures, incompatibility between different types of IT and work procedures, lack of employees' skills, and awareness of technology's capabilities and benefits.

In the investigation of the association between $\mathrm{OC}$ and KMI, it reveals that the barriers of organizational culture positively impact KMI. These findings consist with AlAlawi, et.al. (2007). Based on the results, it is clear that the current study identified many barriers of the organizational culture such as the absence of motivation, reward system, and highly experienced employees retention policy. If the work environment emphasizes competition among individuals and hotels' departments, this may limit KM sharing among hotels' employees. Thus, the above factors pose barriers to KMI (Ghasabeh and Chileshe, 2014; Schepers and Berg, 2007). The third objective of the current study aim to provide strategies to overcome the barriers of KMI will discussed in practical implications.

\section{Practical Implications.}

$\mathrm{KM}$ is not a transient fashion. It is indeed vital for survival and success in an intensive competitive market. The current study provides a comprehensive, holistic framework to identify the barriers of KMI. Thorough barriers of KMI and the model may be expected to result in excessive value for the hotel to prioritize its resources and efforts. Additionally, the current study develops an approach to overcome the KMI barriers in order to enhance the success of KMI. Despite extensive researches conducted on KM in the 
hospitality industry, most of them are veritably limited the impacts of KMI on the hotel performance.

Firstly, senior management should take HR into consideration for being essential and vital to KM success. Effective leadership styles should be chosen, such as transformational leadership, to create a trust learning team work environment, that will apparently lead to the motivation of employees' to share (Connelly, et al., 2000), transfer, store, and disseminate knowledge (Shamim et al., 2017). Literally, senior management should ensure the intellectual rights of ideas. Training courses on KM benefits, communication, and teaching skills should be conducted to encourage employees' to KS, particularly the tacit knowledge to their colleagues through direct contact or by technological methods, creating an excellent hotel learning environment. To add, the management shouldn't overlook the role of traditional training mechanisms as the on-job training, workshops, job rotation, and inductions for new comers to acquire knowledge. On the other hand, it should identify and improve leaders and employees who support learning models at the individual, team and organizational level.

Secondly, the organization should consider KMI a process, not a tool or system; developing KM system should be around the hotels' tasks, not vice versa. Moreover, IT and communication infrastructure should be improved to facilitate the KMI. It should assign a room for electronic library secured to employees' accessibility. As well as conducting a training workshop to raise the employees' computer skills. The hotels' employees look forward to 
using smart phones rather than the desk computer due to its use easiness, regardless of the employees' educational level and computer skills. Further, desk computers are not accessible in hotels to all operational employees such as chefs, food servers, housekeeping attendants, etc. Hence, it is fundamental to construct KMS based on phone Apps to encourage the participation, social interaction and dialogs. In fact, the headquarters' strategy should develop a chain for social media groups such as Whats Apps, Facebook, Twitter, Wiki, and YouTube to KS among employees across hotels' departments and regional departments, to improve the open discussion and questions and answers, regarding the operational issues and problems, and rewarding the best practical solutions. Besides, KMS should be designed to encourage social interaction among employees, leading to the creation and flow of new ideas and knowledge among large number of individuals and teams (Yoopetck, 2010). It should also aim at breaking down geographical, temporal, and organizational obstacles, that leads to increased human capital and retrieve knowledge easily reused (Brown and Kietzmann, 2018). Accordingly, it provides a secure method to preserve intellectual property rights for innovative employees' ideas. The KMS should be designed not only to reduce the consumed time, but to solve a large scale, specific hotel problem and allow to innovation and creativity in service and products delivered to customers. Also, social media ease the knowledge storing and conversion from tacit to explicit form and therefore facilitate the KS and dissemination (Sigala and Chalkiti, 2015) to improve organizations' performance (Farooq, 2018). KMS should permit employees to upload the learned lessons, and their 
experience on groups. Likewise, it should integrate the experts and document the knowledge in $\mathrm{KM}$ repositories to enrich the KM database. It should be designed to reward the best knowledge producers or growth contributors through the departments' directors every quarter. By the same token, it should offer to departments' managers a great and rapid opportunity to control and monitor their subordinates KS activities to consider it in performance appraisal which absolutely lead to increasing employees' behavior in KS. Finally, it should consider economic easily and rapidly, to meet the recent trends and suit various employees' traits and diverse mental abilities.

Thirdly, integrating the concept of $\mathrm{KM}$ in organizational culture OC lead to a more comprehensive view of the relationship among organizational culture $\mathrm{OC}$ and knowledge management KM. The organizational culture must be conducive. Expressly, it must be compatible with the knowledge acquisition, sharing, transferring, and storing. Along these lines, it will establish a vision and beliefs that commensurate with the focus on learning by sharing, and exchange the knowledge among the hotels' departments with different hotels' levels without any fear. The hotel culture must adopt $\mathrm{KM}$ as part of business strategy and commitment by senior managers' to meet the hotels' goals. Also, it highlights the KM importance and benefits to the hotel performance, as well as to the extent to which the hotel may lose a lot of efficiency and efficiency in the absence of such a culture. Developing cooperation and teamwork spirit and increasing the employees' royalty to organization, lead to and abandon the individuality spirit 
and competition among employees and departments that constitutes a hindrance to KMI.

An innovative, democratic, and motivating organizational culture must be available for the employees through providing incentives and rewards (monetary and moral), and raising the economic and social level of knowledge producers. Managers should constantly motivate employees and give them confidence to perform team activities rather than individual ones, which definitely leads to increase their sense of responsibility towards KMI. Furthermore, management should provide a comfortable and flexible work climate and encourage employees to innovate, take greater risks and bravely take responsibility for their mistakes. Still, it should conduct a workshop to set up and develop an organizational culture that allows KS and learning from others. As matter of fact, this might all be achieved only if the senior management is committed to $\mathrm{KM}$ as a tool for continuous communication, competition and prosperity, through planning and designing strategies for the future of $\mathrm{KM}$ to encourage continuous excellent learning climate in the hotel (Dahou, Hacini, and Burgoyne, 2019). To sum up, hotels should be converting into learning organizations.

Effective KMs should incorporate in hotels' strategy and commitment by seniors' managers and encourage the social interaction to improve the hotel performance. It should not only be used to reduce time, but also to provide innovative and creative products and service delivered to customers, and to solve uncommon problems to sustain profitability. 
All in all, the author recommends that the actual contribution of the current study to KMI is considering smart phone applications in social media platforms, information technology and KM practices, as a tool to save time and effort within a practical and applicable framework to integrate them with the expertise and employees' knowledge. This is in will help them to transfer, share and covert tacit knowledge to explicit knowledge through interactive dialogs, which is consistent with the requirements and aspirations of the young generation, and fits their traits. The current study submits the method by which KMS may be applied within a stimulating organizational culture and qualified human resources. Even though, it is detected that social media platforms for hotels are still limited to marketing activities (McCarthy et al., 2010), and are not yet used in KMI; smart phone applications are still in their infancy which definitely presents a great opportunity for hotel chains to be exploited to KMI activities. I hope that our arguments will motivate the decision-makers in hospitality industry to consider the potential of smart phone applications and social media platforms choices as viable KMI tools. Considering the smart phone applications in the current decade alone, and the functional improvements that are still emerging, will play an effective role in the KMI activities. Accordingly, researchers will have to prepare theoretical and practical frameworks to maximize it utilization. Furthermore, hospitality operations should employ the knowledge management to carefully design loyalty programs (Fathy and Zidan, 2017) to be more significantly influence on customer satisfaction and loyalty depending upon which group of customer's they target. 


\section{Limitations and Future Research}

Although current research offers valuable and critical contributions, it still has several limitations that pave the way for further suggestions. The current study focused mainly on four and five star hotels. It is limited to the hotel industry, and cover only Alexandria city, Egypt. An extensive future research has to conduct in other sectors of the hospitality industry. Despite the fact that the current study has investigated the barriers of KMI in four and fivestar hotels, but other researches have to be conducted in the lower hotels grade, which often suffer from many and different KM barriers than the current research. The current study opens promising avenues for future comparative researches between the hotels types, hotels grades, and independent hotels and chain-hotels

\section{References}

- Al-Alawi, A. I., Al-Marzooqi, N. Y. and Mohammed, Y. F. (2007), "Organizational culture and knowledge sharing: critical success factors", Journal of Knowledge Management, Vol, 11. No. 2, pp. 22-42. https://doi.org/10.1108/13673270710738898.

-Anderson, J.C. and Gerbing, D.W. (1988), "Structural equation modeling in practice: a review and recommended two-step approach", Psychological Bulletin, Vol. 103, No. 3, pp. 411-423.

- Barbara M. Byrne (2010), Basic Concepts, Applications, and Programming, university of north Carolina, USA. 
- Boroujerdi, S.S., Hasani, K. and Delshab, V. (2020), "Investigating the influence of knowledge management on organizational innovation in higher educational institutions", Kybernetes. Vol. 49 No. 2, pp. 442-459

- Brown C. A. and Kietzmann, J. (2018), "Strategic knowledge management and enterprise social media", Journal of Knowledge Management, Vol. 22 Issue: 6, pp.1288-1309. https://doi.org/10.1108/JKM-082017-0359

- Cheng, X. (2010). "A systematic review of knowledge management research in the hospitality and tourism industry", A Published thesis submitted in partial fulfillment of the requirements for the Master of Science in Hotel Administration William F. Harrah College of Hotel Administration. Graduate College University of Nevada, Las Vegas. USA.

- Connelly, M.; Gilbert, J.; Zaccaro, S.; Threlfall, K.; Marks, M.; and Mumford, M. (2000), "Exploring the relationship of leadership skills and knowledge to leader performance" Leadership Quarterly, Vol. 11, pp. 65-86. https://doi.org/10.1016/S1048-9843(99)00043-0

- Cooper, C. (2006), "Knowledge management and tourism", Annals of Tourism Research, Vol. 33, No. 1, pp. 47-64. 
- Cooper, C. (2014), Managing tourism knowledge, Routledge, London, England.

- Farooq, R. (2018), "A conceptual model of knowledge sharing", International Journal of Innovation Science, Vol. 10, No. 2, pp. 238-260. https://doi.org/10.1108/IJIS-09-2017-0087

- Fathy, E, A. (2018). "Issues faced by hotel human resource managers in Alexandria, Egypt". Research in Hospitality Management, Vol, 8, No. 2, pp 115-124. https://doi.org/10.1080/22243534.2018.1553381

-Fathy,E.A. and Zidan,H.A.( 2017), Do Loyalty

Program in the Airline and Hotel Industries affect Customer Satisfaction and Loyalty?, International Journal of Heritage, Tourism and Hospitality, Vol. (11), No. (3/2).

- Fornell, C., \& Larcker, D. F. (1981). "Evaluating structural equation models with unobservable variables and measurement error". Journal of Marketing Research, Vol.18, No.3, pp. 39-50.

- Jogaratnam, G. (2017), "The effect of market orientation: entrepreneurial orientation and human capital on positional advantage: evidence from the restaurant industry", International Journal of Hospitality Management. Vol. 60, No. pp. 104-113. http://www.sciencedirect.com/science. 
- Gay, L. R., and Diehl, P. L. (1992), "Research Methods for Business and Management". Maxwell Macmillan International, New York, USA.

-Dahou, K.; Hacini, I.; Burgoyne, J. (2019). "Knowledge management as a critical success factor in developing international companies' organizational learning capability". Journal of Workplace Learning. Vol. 31 No. 1, pp. 2-16

- Hallin, C. A., and Marnburg, E. (2007), "Knowledge management in the hospitality industry: A review of empirical research", Tourism Management. https://doi:10.1016/j.tourman.2007.02.019.

- Hair, J., Black, W, Babin, B., and Anderson, E. (2014), Multivariate data analysis (7th ed.). Person, Edinburgh, England.

- Hislop, D.; Bousa, R.; and Helms, R. (2018), Knowledge management in organizations, (4th ed), Oxford University Press. Oxford, England.

- Hong, D. G.; Koo, C. H.; and Suh, E. H. (2009). "Overcoming barriers of knowledge sharing through communities of practice: A case study of steel company. Korean journal of Information Systems Review, Vol. 11, No, 2, pp. 131-145. https://doi.10.1016/j.eswa.2011.04.072. 
- Kahle, E. (2002), "Implications of 'new economy' traits for the tourism industry", Journal of Quality Assurance in Hospitality and Tourism, Vol, 3, No. 3-4, pp. 5-23. https://doi/abs/10.1300/J162v03n03_02

- Kline, R.B. (2011), Principles and Practice of Structural Equation Modeling, 3rd ed., Guilford Press, New York, NY.

- Khajouei, H.; Jamshidi, M.J.; and Nasrabadi, H. (2016), "Investigation and prioritization of cultural barriers against implementation of knowledge management in Kerman Regional Electric Company. International Journal of Knowledge Management Studies, Vol 7, No. 3-4, pp. 257-269.

- Črnjar K. and Dlačić, J. (2014), "Critical success factors for knowledge management Implementation in hotel enterprises. Human capital without boarder: knowledge, and learning for quality of life. Management, knowledge and learning. International conference. 2014. 25-27 June 2014. Portoroz, Slovenia. https://ideas.repec.org/s/tkp/mklp14.html (accessed 20 March 2017).

- Levy, M. (2011), "Knowledge retention: minimizing organizational business loss". Journal of Knowledge Management, Vol. 15, No. 4, pp. 582-600. https://doi.org/10.1108/13673271111151974. 
-Long, D. D. (1997), Building the Knowledge-Based Organization: How Culture drives Knowledge Behaviors. working paper, Center for Business Innovation, 6 April, 2016 from http://www.providersedge. com/docs/km_articles/Building_the _ KnowledgeBased_Organization.pdf].

- McDermott, R and O'Dell, C. (2001), "Overcoming cultural barriers to sharing knowledge". Journal of Knowledge Management, Vol. 5, No. 1, pp. 76-85. https://doi.org/10.1108/13673270110384428

- McCarthy, L.; Stock, D., and Verma, R. (2010), "How travelers use online and social media channels to make hotel-choice decisions". Cornell Hospitality Report, Vol. 10, No. 18, pp. 4-18.

- Ghasabeh, M. S.; and Chileshe, N. (2014), "Knowledge management: Barriers to capturing lessons learned from Australian construction contractors perspective", Construction Innovation, Vol. 14, No. 1, pp.108-134, https://doi.org/10.1108/CI-06-2013-0026

- Neuman, W. (2003), Social research methods: Qualitative and quantitative approaches (5th ed.). Allyn and Bacon, Boston, USA.

- Nunnally, J.C. (1978). Psychometric theory. (2 th ed.)., McGraw-Hill, New York, USA. 
-Salem, I, E. (2014), "Toward better understanding of knowledge management: Correlation to hotel performance and innovation in five-star chain hotels in Egypt", Tourism and Hospitality Research, Vol. 14, No. 4, pp. 176-196.

-Schepers, P.; and van den Berg, P.T. (2007), "Social factors of work-environment creativity", Journal of Business and Psychology, Vol. 21 No. 3, pp. 407-428.

- Schmitt, U. (2019), "Designing decentralized knowledge management systems to effectuate individual and collective generative capacities", Kybernetes, Vol. 49 No. 1.

-Shamim, S.; Cang, S.; and Yu, H., (2017), "Supervisory orientation, employee goal orientation, and knowledge management among front line hotel employees" International Journal of Hospitality Management, Vol. 62, pp. 21-32.

- Sigala, M. (2016) "Learning with the market: A market approach and framework for developing social entrepreneurship in tourism and hospitality", International Journal of Contemporary Hospitality Management, Vol. 28, No. 6, pp.1245-1286, https://doi.org/10.1108/IJCHM-06-2014-0285.

- Sigala, M.; and Chalkiti, K.. (2015), "Knowledge management, social media and employee creativity", 
International Journal of Hospitality Management, Vol. 45, pp. 44-58

- Uriarte, F.A., (2008), Introduction to knowledge management. ASEAN Found., 45-65.

- Yang, J.-T. (2004), "Qualitative knowledge capturing and organizational learning: Two case studies in Taiwan hotels", Tourism Management, Vol. 25, No. 1, pp. $421-428$.

- Yang, J.T.; and Wan, C.S. (2004). "Advancing organizational effectiveness and knowledge management implementation. Tourism Management, Vol. 29, No. 1, pp. 593- 601.

- Yoopetck C (2010), "The model of knowledge acquisition: the study of SMEs in the Thai Hospitality Industry", World Academy of Science, Engineering and Technology, Vol. 42, pp. 351-354.

- Yih-Tong, S.P.; and Scott, J. (2005), "An investigation of barriers to knowledge transfer", Journal of Knowledge Management, Vol. 9, No. 2, pp. 75-90.

- Yuen T. J.; and Majid M. Sh. (2007). "Knowledgesharing patterns of undergraduate students in Singapore", Library Review, Vol. 56, No. 6, pp. 485494. 
-Zeraati, H., Rajabion, L., Molavi, H. and Navimipour, N.J. (2019), "A model for examining the effect of knowledge sharing and new IT-based technologies on the success of the supply chain management systems", Kybernetes, Vol. 49, No. 2. pp. 229-251 